REVIEW

\title{
Education of senior house officers: current challenges
}

\section{S Carr}

Postgrad Med J 2003;79:622-626

Over recent years several factors have impacted upon the education of doctors in training in medicine and other specialties. These factors include the European Working Time Directive and shift patterns of working, increasing service demands, changes in the examination and assessment processes, and clinical governance issues. In addition, over the next few years further changes will take place with the implementation of "Modernising Medical Careers" document and the establishment of the new Postgraduate Medical Education and Training Board. This article attempts to review the effects of these changes on education of junior doctors and to suggest some possible ways to address these challenges.

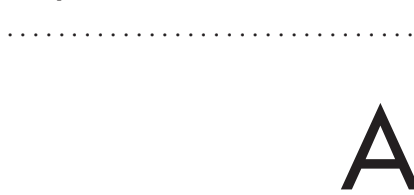

$\mathrm{A}$ doctor enters the senior house officer (SHO) grade after successful completion of a year as a pre-registration house officer. The fundamental aims of SHO training have been clearly defined by the General Medical Council in The Early Years ${ }^{1}$ document and in further detail for doctors training in the medical specialties in the Core Curriculum for Medical Senior House Officers from the Royal College of Physicians. $^{2}$

The intended outcomes of SHO training are:

1. To further develop a range of generic medical knowledge and skills and appropriate attitudes.

2. To begin to develop specialty specific knowledge and competencies.

3. To further develop personal and transferable skills (communication skills, teaching, etc).

4. To improve understanding of management issues, audit, research, clinical effectiveness, and clinical governance.

Over recent years it has been recognised that there has been an increasing number of pressures impacting upon the training of SHO in medical and other specialties.

Firstly, as a consequence of an increasing awareness that the hours worked by doctors in training were unacceptable for their own welfare and that of their patients, legislation was introduced to limit the hours of work of doctors in training. The introduction of the European Working Time Directive ${ }^{3}$ and the New Deal document ${ }^{4}$ had a profound effect on the working patterns of doctors in training and currently presents a major challenge to the provision of effective educational programmes. The legal hours of work for doctors in training will again be reduced from 56 hours in May 2004 to 48 hours in 2009-12 thereby further increasing the difficulties presented to delivering effective training.

In certain "hard pressed" specialties this reduction in hours has led to a change from a traditional on-call rota to a shift system of working.

\section{EFFECTS OF SHIFT WORKING PATTERNS ON THE EDUCATION OF DOCTORS IN TRAINING}

The change in working patterns from a traditional on-call pattern to a shift system of working resulted in a reduction in the total number of hours worked which automatically led to a reduction in the quantity of time available for learning. However, there are a number of other additional factors to be considered when considering the effects of shift working patterns on the education and training of doctors. In general, doctors in training are now on duty for fewer hours but the work intensity has increased in the out of hours period as there are far fewer doctors on duty at any one time. This increase in work intensity leads to a further reduction in time and opportunity for experiential learning, less opportunity for personal reflection and interaction and learning with colleagues (that is, consultants, registrars, and fellow SHOs). Previously, shared learning within the medical team was a common way of learning and reviewing cases seen with one's registrar and senior registrar while on-call and then presenting the cases on the consultant ward round was a learning opportunity. The new ways of working have reduced such learning opportunities as often the doctor will be one of few or the only person on duty in an area for the shift and the session may end before he has had sufficient opportunity to interact with the consultant on duty who is performing the ward round.

Shift working has also reduced the opportunity for SHOs to attend planned formal educational sessions due to night shift patterns and rostered days off. ${ }^{5}$

Several authors have studied the impact of the New Deal arrangements and shift working on training of junior doctors and results have been conflicting. ${ }^{5-13}$

Two studies have reported a positive influence of shift working on the education of SHOs. Paice in a study of SHOs in the North West Thames deanery concluded that the educational quality

Abbreviations: PMETB, Postgraduate Medical Education and Training Board; SHO, senior house officer 
of posts was more do with working in a well organised, well supervised educational environment than with putting in long hours of work. ${ }^{6}$ This paper concluded that the New Deal was compatible with good SHO training. Another study of surgical trainees in Scotland came to similar conclusions. ${ }^{7}$ However a greater number of authors have concluded that reduced hours of work and shift patterns have had a detrimental effect on training. The UK is not unique in this respect: studies have shown that ${ }^{8-10}$ a number of countries faced similar difficulties when reducing junior doctors hours and managed the transition in different ways. In Denmark the working week has been reduced to 37 hours a week supported by a large increase in number of doctors. ${ }^{9}$

Australian studies concluded that reduced hours of work did have a negative effect on training for three reasons ${ }^{8-10}$ :

1. Lack of time for formal and independent study.

2. Lack of motivation due to fatigue.

3. Extended hours' work patterns failed to provide necessary supervision and feedback for effective learning.

Another study of SHOs in paediatrics in a single region concluded that shift rotas were universally felt to be detrimental to training, leading to both a reduction in inservice learning and attendance at formal educational sessions. The inflexibility of shift rotas also often made applications for study leave unsuccessful. ${ }^{5}$ Baldwin et al demonstrated the unpopularity of shift working among SHOs and that they perceived this to have produced detrimental effects on patient care and training. ${ }^{11}$ Kapur and House studied the psychological morbidity of 60 medical house officers in two teaching hospitals over a year using a health and job satisfaction questionnaire. ${ }^{12}$ The 59 respondents reported that shift working significantly reduced scores for job satisfaction $(\mathrm{p}<0.001)$ and perceived quality of training $(p<0.001)$. Kapur challenges that the positive findings of Paice et $a l^{6}$ were related to a large increase in available resources at the time of the study. ${ }^{13}$

On balance, the evidence suggests that shift working has had a detrimental effect on learning for doctors in training. The reduction in working hours and consequent changing nature of the learning opportunities resulting from a reduction in hours of work has to be offset by an increase in the quality of the learning experiences. ${ }^{8} 9$ In the light of such research it is imperative that we consider these issues in the design and delivery of our future training programmes.

\section{CHANGE IN WORKING PATTERNS}

In addition to the reduction in working time available for learning there are other effects of the change in working patterns on the education of SHOs. The introduction of complex rotas in acute specialties has led to the loss of the traditional "firm" structure of medical teams in many hospitals. In the past a group of doctors at different grades always worked together for periods of at least six months and often longer. This system led to a strong "team" spirit and a system of mentorship. The consultant has a strong sense of responsibility to educate and train the junior doctors who are assigned to his or her team. The rotas now in operation have led to an erosion of this system and a loss of mentorship in training, which may have detrimental effects on SHOs' education. This reinforces the need to develop a more robust system of educational supervision for doctors in training and a reliable system for documentation of abilities and competencies.

\section{NHS SERVICE COMMITMENTS}

The duties of SHOs have traditionally been designed to fulfil a service commitment and often SHOs lose valuable training opportunities while performing repetitive tasks on the ward. ${ }^{14}$ A survey in the Yorkshire deanery showed that in 1997 only $47 \%$ of SHOs attended outpatient department clinics regularly and approximately a third of SHOs in the region did not gain sufficient clinical experience to prepare themselves for specialist registrar posts despite sufficient clinical material being available. ${ }^{15}$

Similarly, Flett et al reported that in general medicine service commitments were a major obstacle to attendance at formal educational sessions in the Trent region. ${ }^{16}$

Hopefully, some of these issues will be addressed by initiatives such as the "Changing Workforce" programme, ${ }^{17}$ which is currently reviewing the roles of staff groups within the NHS.

\section{CLINICAL GOVERNANCE}

The General Medical Council and Royal Colleges now state a need to broaden the training provided to doctors to encompass personal, generic skills, an appreciation of management issues, and clinical governance.

Concerns of the government, the media, and the public about quality of clinical care have focused attention on clinical competence. It is recognised that it is no longer sufficient for individuals to consider themselves competent but that there is a need for professionals to demonstrate they are clinically able to perform certain roles. It is important to incorporate this principle into a doctor's early clinical training and document competencies in a more formalised fashion. In addition, serious clinical incidents have occurred in the UK in recent years relating often to inadequate clinical skills training. As a consequence, the Clinical Negligence Scheme for Trusts now requires assessment of the competencies of doctors in training in a more formalised fashion before a trust can be considered for level 2 accreditation.

There are difficulties with the implementation of assessment of clinical competencies for doctors at SHO grade with the system in its current form. At present, the experience a SHO receives is not uniform as each doctor is exposed to a variable number and type of medical specialties as they go through a two year training rotation or a series of six month posts. This problem strengthens the need for a formal training programme and a formative type assessment as training progresses.

\section{CHANGES IN ASSESSMENT PROCESS}

Traditionally the examination for Membership of the Royal College of Physicians undertaken by SHOs before progressing to the registrar grade took the form of two written examinations and an examination of clinical skills. The format of the examination has been changed to include examination of communication skills, history taking, and ethical issues. This change in both the curriculum and assessment process reinforces the need to provide adequate training for SHOs in generic skills and to begin to assess competencies in these areas.

\section{FUTURE PROPOSALS}

Recently, Sir Liam Donaldson and the government produced proposals for reform of the SHO grade that describes the development of a foundation programme of training followed by a two year period of basic specialist training, which will be time limited and managed by a programme director. ${ }^{18} 19$ This proposal if ratified will have a major influence on the system of training for SHOs in all specialties. The proposals also include an intention to review and increase the relevance of the assessment process. A new supervisory body will also be introduced: the Postgraduate Medical Education and Training Board (PMETB) from October 2003. The PMETB will run alongside the Specialist Training Authority and the 
Joint Committee for Postgraduate Training in General Practice for one year. The new body consisting of lay representatives, doctors, Royal College representatives, and other stakeholders in education-that is, NHS trusts will supervise and certify medical education and training.

\section{THE WAY FORWARD}

As described above, the radical changes in the working practices of doctors in training have undermined some of the traditional informal ways of learning and a more structured and sophisticated approach needs to be developed to cope with the changing territory. Doctors are adult learners and in developing future educational programmes we need to adopt a more "andragogic" approach where the teacher facilitates the learner's learning and move away from the traditional "pedagogic" teaching situations..$^{20}{ }^{21}$ One can consider this in the context of "linear and experiential" curriculae.

\section{Linear curriculum}

There is a need to improve the structure and accessibility of the formal programme of educational opportunities in addition to maximising the many educational opportunities that arise from reflection upon daily clinical experiences. ${ }^{21}{ }^{22}$ To improve access to the linear curriculum a model of integrating formal educational programmes within the shift pattern has been shown to be workable ${ }^{16}$ in an accident and emergency setting. A different model may be to structure a programme of educational modules repeated on several occasions to accommodate individual shift patterns. ${ }^{21}$ This type of approach will require more teaching sessions to enable repeat sessions and improved links between specialties to integrate training on areas of common ground as far as possible. In addition to improved formal educational programmes designed to accommodate working patterns, new approaches also need to be encouraged. A proportion of the linear curriculum could be provided by distance learning which can be undertaken at times appropriate to the doctor's working hours. The Royal College of Surgeons have successfully introduced such a package in the STEPS course which has been well evaluated ${ }^{23}$ and the Royal College of Physicians have a CD-ROM based learning package called "Medical Masterclass", ${ }^{24}$ which is popular among trainees. There are now numerous websites available for trainees mainly for examination preparation, but there is a continuing need to increase and improve this resource. An improved information technology system within large trusts would also improve communication about learning opportunities in other departments, which trainees could access when convenient.

The structure, content, and relevance of a training course for the purpose of SHO training needs to be continuously evaluated and audited and modifications made if required. Johnasen showed that audit was a useful and effective tool for this purpose..$^{25}$

\section{Experiential learning in clinical practice}

In addition to a formal education programme it is essential that a doctor in training makes maximum use of work based or experiential learning opportunities. Learning by doing a particular skill or task is a very valuable educational technique. This active process of learning helps maintain the learner's motivation and is usually highly effective. If the learner has a personal stake in the learning then there is a built in assurance of greater interest and effort.

It is very important that the potential of experiential learning opportunities is maximised in the training of doctors. Traditional experiential learning situations-that is, consultant ward rounds-continue to be highly valued by trainees. Talbot found the ward round to be a very useful teaching resource after a questionnaire sent to 500 SHOs in North Trent. ${ }^{26}$ Trainees found the ward rounds particularly

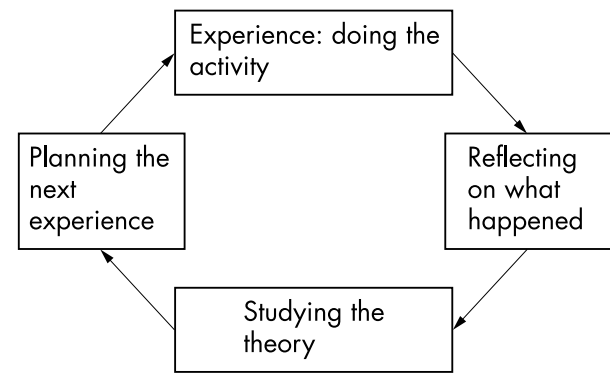

Figure 1 A simplified Kolbs experiential learning cycle. ${ }^{27} 28$

useful when learning professional attributes and skills but less useful to learn clinical science principles and management strategies. The clinic setting can also be an extremely valuable experiential learning resource.

In his book in 1984 Kolb described a four stage model of experiential learning. ${ }^{27}$ The main points of experiential learning that Kolb considered important were as follows:

1. The learner is involved in the active exploration of the experience.

2. The learner must reflect on the experience in a critical way.

3. Learners must be committed.

4. The learner must have scope to achieve some independence from the teacher.

5. The teacher imposes structure on the learning experience.

6. The learner must be exposed to the experience.

7. The learner must feel safe and supported.

8. The experiential learning must be supported by other appropriate learning activities.

As encompassed in Kolbs experiential learning cycle, ${ }^{27} 28$ and more recently discussed by Johnson, ${ }^{21}$ it is essential that protected time for a reflective element is included in the timetable of both teachers and learners if this mode of learning is to be effective. At the present time this is a major barrier to maximising opportunity for experiential learning in the clinical environment of the NHS. Often the consultant is faced with a range of competing pressures in a single situation-that is, in every outpatient clinic there is a high volume of patients to be seen, waiting times to be met, and constant interruptions from incidental clinical situations arising on the ward. The patient also has changing expectations of a consultation and often does not share the doctor's enthusiasm to utilise their consultation as a teaching opportunity. In addition, there are often numerous different levels of undergraduate medical students and postgraduate doctors seeking training within a clinic, not to mention the occasional overseas clinical observer, medical student on an elective visit, or a nurse undertaking a special assignment. If these challenges are to be met and experiential learning opportunities improved these issues need to be addressed both for ward round, bedside, and clinic based teaching. For example one solution may be a rotation of doctors in training and medical students through a designated teaching clinic where the teacher is aware of the requirements of the trainees in advance, patients are willing and informed participants in a specifically arranged clinic session, and incidental interruptions are minimised as far as possible. This can only be achieved by injection of considerable resources to allow adequate training of clinical and educational supervisors and to provide protected time for trainees and trainers to reflect upon and learn from clinical experiences. 


\section{Shared learning between and within professional groups}

Within the NHS doctors work within both a medical team and a multiprofessional clinical team; it is therefore logical that the members of the team should learn together. Studies have shown that SHOs are positive about learning and working as members of the medical team. Gibson and Campbell surveyed 650 SHOs in Northern Ireland and reported that the respondents felt group learning improved patient care and knowledge acquisition. ${ }^{29}$ Great potential exists within the hospital environment for shared learning and this may provide an extension to experiential and self directed learning. ${ }^{29}$ Uniprofessional shared learning already exists in several forms: (1) educational supervisors and mentors supporting trainees, (2) professional meetings, for example, the grand round, and (3) peer assisted learning where groups of trainees with same aims, that is, preparation for PACES examination, will facilitate each other's learning.

The General Medical Council and the government in the New NHS plan ${ }^{30}$ encourage us to develop multiprofessional shared learning opportunities. There is also a call for joint training in certain key areas and the development of a core curriculum for NHS staff. It is important to patient care that nurses and doctors develop a mutual respect and understanding if interprofessional relations are to improve. Some studies have evaluated multiprofessional shared learning. Hewstone et al, ${ }^{31}$ Carpenter, ${ }^{32}$ and Carpenter and Hewstone ${ }^{33}$ identified measurable outcomes in medics, nurses, and social workers that learnt together. They reported significant positive changes in attitude towards other professional groupings but there was no evidence to indicate that this modification was permanent. Practical skills laboratories where nurses and doctors train together have been seen to be successful in a number of studies. ${ }^{34}{ }^{35}$ However, little was found to substantiate this belief in measurable terms. Reeves et al undertook a pilot project for pre-registration house officers and newly qualified nurses to focus upon areas of the hospital service that could be improved including discharge planning and intravenous drug administration. ${ }^{36}$ The participants were asked to work together to solve problems based around clinical scenarios. The study concluded that such sessions encouraged collaboration between members of the clinical team for the benefit of patient care and addressed some issues important to clinical governance. ${ }^{36}$ Several authors have expressed concerns about shared learning stating that the professions within healthcare are distinct and should remain separate. ${ }^{37} 38$

On balance there is support within the literature for exploring uniprofessional and multiprofessional shared learning, the perceived benefits being improved interdisciplinary working, improved communication, acquisition of new skills and knowledge. There are also a number of obstacles identified. This is one area that could be explored further in SHO training with the development of multiprofessional shared learning initiatives.

Nationally the government is developing the concept of shared learning with the establishment of the University of the NHS, ${ }^{39}$ which will provide a range of courses aimed to improve the skills of all healthcare workers.

\section{Educational supervision and appraisal}

The majority of consultants working in the NHS are involved in training of doctors and this role has been emphasised by the publication of the General Medical Council documents Good Medical Practice ${ }^{40}$ and The Doctor as Teacher. ${ }^{41}$ In these documents the obligation of all consultants with trainees to provide effective clinical supervision to less experienced colleagues is outlined.
However, with the change in the patterns of working there is a recognised need for a more sophisticated approach to educational supervision of doctors in training. In addition to a clinical supervisor who supervises daily clinical activity and acts as a professional role model a junior doctor also needs to have an educational supervisor to fulfil three main roles. ${ }^{42}$

1. Educative role: to develop a learning plan with the trainee, help the trainee understand how they learn to make more effective use of available opportunities, to review progress, and provide feedback at regular intervals.

2. Supportive role: to discuss and help trainees deal with problems faced during work-that is, coping with death, difficult patients, etc.

3. Managerial function: appraising and assessing the trainee's work against accepted standards.

While most consultants have the good clinical knowledge and clinical skills to act as a clinical supervisor not all consultants will have the skills or the desire to become educational supervisors and specific training and time needs to be provided for this essential role.

\section{CONCLUSION}

There are numerous challenges to the provision of effective education for SHOs at the present time. The pressures of NHS service commitments need to be addressed if we are to improve education and some initiatives including the "Changing Workforce" project may help ease some of these pressures by reviewing traditional roles and working practices.

The development of high quality formal training programmes can address some of the challenges relating to reduced hours of work for SHOs adapted to accommodate the shift patterns of working. Alongside such development we need to develop a robust system for educational supervision and appraisal and to become educationally more sophisticated in the future to cope with the multiple challenges to doctors' learning. The institution of a formal training programme for SHOs headed by a programme director as proposed by Donaldson ${ }^{18}$ would help facilitate many aspects of this.

Trusts need to be encouraged by educational institutions to train educational supervisors and to include sessions for teaching and educational supervision in the contracts of some consultants. We need to treat doctors in training as "adult learners" and move towards a philosophy where the teacher facilitates the learning rather than provides the teaching, as had been the traditional model within medicine. In the future training programmes should look to utilise the advances in information technology and distance learning, which could facilitate some aspects of medical training especially for those involved in shift working.

\section{REFERENCES}

1 General Medical Council. The early years. London: GMC, 1998.

2 Royal College of Physicians. A core curriculum for senior house officers in general (internal) medicine and the medical specialties. London: RCP, 2001.

3 Department of Health. Hours of work of doctors in training: the new deal. London: Department of Health, 1991.

4 NHS Management Executive. Junior doctors - the new deal. London: Department of Health, 1991.

5 Davies J, Tan K, Jenkins HR. The current status of senior house officer postgraduate education in a single region. Med Educ 2000;34:367-70.

6 Paice $\mathbf{E}$. Is the new deal compatible with good training? A survey of senior house officers. Hospital Medicine 1998;59(1):72-4.

7 Hurley PA, Paterson-Brown S. Senior house officer training: some myths exposed. J R Coll Surg Edinb 1999;44:324-7.

8 Association for the Study of Medical Education. Education and shift working: an oxymoron? London: Association for the Study of Medical Education, 2002. 
9 Scallan AS. A review of the literature. Education and shift working: an oxymoron? London: Association for the Study of Medical Education, 2002:2-6.

10 Australian Medical Association. Risk assessment of junior doctors rosters. Australia: AMA, 2001 (http://domino.ama.com.au/).

11 Baldwin PJ, Newton RW, Buckley G, et al. Senior house officers in medicine: postal survey of training and work experience. BMJ 1996;314:740-3.

12 Kapur N, House A. Job satisfaction and psychological morbidity in medical house officers. J R Coll Physicians 1997;31:162-7.

13 Kapur N. Improved training may have more to do with money than new shifts. BMJ 1997;314:1829.

14 Dillner L. Senior house officers: the lost tribes. BMJ 1993;307:1549-51.

15 Bunch GA, Bahrami J, Macdonald R. Senior house officer training: training must be more structured. BMJ 1997:314:1828-9.

16 Flett $A$, Baker $M$, Williams J. Formal education programmes for senior house officers: comparisons of experience in three hospital specialties. Postgrad Med J 2001;77:650-3.

17 NHS Modernisation Agency. Changing workforce programme. New ways of working in healthcare. NHS Modernisation Agency, 2002 (http:// www.modern.nhs.uk/).

18 Donaldson L. Unfinished business: proposals for reform of the senior house officer grade. London: Department of Health, August 2002.

19 Department of Health. Modernising medical careers. The response of the four UK Health Ministers to the consultation on unfinished business. London: Department of Health, 2003.

20 Knowles M. The adult learner-a neglected species. Houston: Gulf Publishing, 1978.

21 Johnson N. Training of junior doctors: the responsibility of consultants and trainers. Postgrad Med J 2001;77:745-6.

22 Parsell G. Senior house officer training: time for reform. Med Educ 2001;35:92-3.

23 Carpenter R. Senior house officer education in the UK: the contribution of a distance-learning course (MRCS-STEP). Ann R Coll Surg Engl 1999;81:228-9.

24 Royal College of Physicians. Medical masterclass. Firth J, ed. Oxford: Blackwell Science, 2001

25 Johnasen A. Using audit to improve senior house officer training. BMJ 1997;73:798-801.
26 Talbot M. Professional modeling: a questionnaire study of junior doctors attitudes to aspects of experiential learning on the hospital ward round. Med Educ 2000;34:312-5.

27 Kolb DA. Experiential learning-experience as the source of learning and development. Englewood Cliffs, NJ: Prentice-Hall, 1984.

28 Cotton J. The theory of learning: an introduction. Experiential learning London: Kogan Page, 2000:109-17.

29 Gibson DR, Campbell RM. The role of cooperative learning in the training of junior hospital doctors: a study of paediatric senior house officers. Medical Teacher 2000;22:297-300.

30 Department of Health. NHS Plan, a plan for investment, a plan for reform. London: Department of Health, 2000.

31 Hewstone M, Carpenter J, Franklyn-Stokes A, et al. Intergroup contact between professional groups. Two evaluation studies. Journal of Community and Applied Social Psychology 1994;4:347-63.

32 Carpenter J. Doctors and nurses: stereotypes and stereotype change in interprofessional education. Journal of Interprofessional Care 1995;9:151-61.

33 Carpenter J, Hewstone M. Shared learning for doctors and social workers: evaluation of a programme. British Journal of Social Work 1996;26:239-57.

34 Jackson S. The case for shared training for nurses and doctors. Nursing Times 1996;26(92):40-1.

35 Mclndoe A. The future face of medical training- ship shape and Bristol fashion. British Journal of Theatre Nursing 1998;8(8):7-9.

36 Reeves S, Freeth R, Wood D. A joint learning venture between new nurses and junior doctors. Nursing Times 2000;96(38):39-40.

37 Farmer E. Medicine and nursing: a marriage for the 21 st century. British Journal of Nursing 1995:4:793-4.

38 Castledine G. A nursing "peace" $v$ medical "war" model. British Journal of Nursing 1999;8:62.

39 University of the NHS. Learning for everyone. London: University of the NHS 2002 (http://www.nhsu.nhs.uk/).

40 General Medical Council. Good medical practice. London: GMC, 2001.

41 General Medical Council. The doctor as teacher. London: GMC, 1999.

42 Freeth R. Supervision. BMJ 2001;323:2-3.

FILLER

\section{Child safety locks}

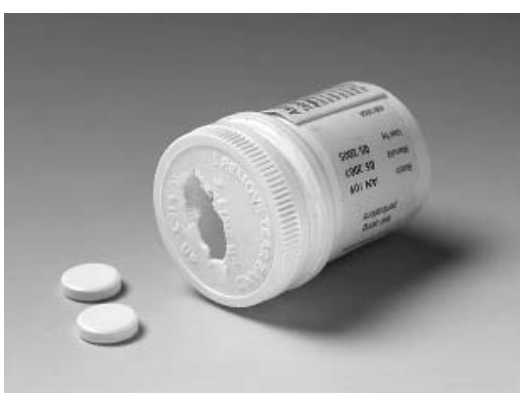
75 year old man on thyroxine replacement and ascorbic acid presented with
hypothyroidism. Due to a complex child safety lock he had found it impossible to
open the container holding thyroxine. He did, however, manage to take his ascorbic
acid (see fig 1).
Pharmacists and doctors should ensure that patients are able to open containers with
complicated child safety devices.

A J Kinder, S Gardner, P Wurm Department of Medicine, Leicester Royal Infirmary, Infirmary Square, Leicester LE1 5WW, UK; alisonkinder@dsl.pipex.com 